Supporting Information (SI) for

\title{
Mechanochemical Modification of Oxygen/Nitrogen Species on Surface of Hard Carbon for Improved Sodium Storage
}

Xinmei Gao ${ }^{a}$, Hanqing Zhao ${ }^{a}$ *, Shujun Zhang ${ }^{a}$, Hanting Shen ${ }^{a}$, Zhong Li $^{a}$ *

${ }^{\text {a }}$ State Key Laboratory of Clean and Efficient Coal Utilization, Taiyuan University of

Technology, Taiyuan 030024, China

* Corresponding author

Email: zhaohanqing@tyut.edu.cn; hanqing_zhao1@163.com (Dr. H. Zhao)

lizhong@tyut.edu.cn (Prof. Z. Li)

Number of pages: 12

Number of figures: 6

Number of tables: 2 


\section{EXPERIMENTAL SECTION}

\subsection{Materials Preparation}

In brief, a $0.5 \mathrm{M}$ glucose aqueous solution was added into a Teflon-lined autoclave and heat-treated at $180{ }^{\circ} \mathrm{C}$ for $12 \mathrm{~h}$. After cooling to room temperature, the carbon nanosphere precursor was obtained by washing with distilled water and drying at $60{ }^{\circ} \mathrm{C}$ overnight. Afterward, $0.5 \mathrm{~g}$ carbon nanosphere precursor was thoroughly mixed with $2 \mathrm{~g}$ urea in an agate mortar. Then, the $\mathrm{N}$-doped carbon nanospheres (NCS) were obtained by annealing the as-prepared mixture at $800{ }^{\circ} \mathrm{C}$ for $2 \mathrm{~h}$ with a heating rate of $2{ }^{\circ} \mathrm{C} \min ^{-1}$ under flowing argon.

$\mathrm{N}$-doped carbon nanospheres $(\mathrm{NCS})$ and agate balls (diameter $=5-10 \mathrm{~mm}$ ) with a weight ratio of 1:10 were sealed in a $\sim 25 \mathrm{~mL}$ agate milling jar of the planetary ball-milling machine (Tianchuang powder technology, XQM-0.2A). The resultant products were separated from the agate balls. The mechanochemically treated NCS were prepared by agitating with 250,500 , and $750 \mathrm{rpm}$ for $48 \mathrm{~h}$, denoted as NCS-250, NCS-500, and NCS-750, respectively.

\subsection{Materials Characterization}

The structural characteristics were examined by X-ray diffraction (XRD, Rigaku MiniFlex600, $\lambda=1.54 \AA, \theta=10^{\circ}-80^{\circ}$ ) and Raman spectra (Thermo Fischer DXR). The morphology was observed through Scanning electron microscope (SEM, JEOL JSM-7900F). The specific surface area and the pore size distribution were obtained using nitrogen adsorption apparatus (Beishide 3H-2000 PS2). X-ray absorption near-edge structure (XANES) spectroscopy was collected at 4B9B beamline of the 
Beijing Synchrotron Radiation Facility to investigate the structural defects and surface functional groups. The XANES spectra were obtained in the total electron yield (TEY) mode with an energy resolution of $0.1 \mathrm{eV}$. Considering that the $\mathrm{O}-/ \mathrm{N}$-containing functional groups on the surface of carbon are the key issues in this work, we cannot treat the surface of samples by the Ar-etching or high-temperature calcination. Therefore, the fresh samples for XANES measurements were fabricated, vacuum-sealed and placed in the argon-filled glove box immediately after the mechanochemical treatment. The surface heteroatom contents and bonding configurations were characterized by X-ray photoelectron spectroscopy (XPS, Thermo Fischer Escalab 250Xi). Diffuse Reflectance Infrared Fourier Transform Spectroscopy (DRIFTS) measurements were performed using a Fourier transform spectrometer (BRUKER, TENSOR II) in the wavenumbers range of $800-4000 \mathrm{~cm}^{-1}$. The elemental compositions of carbon, hydrogen, nitrogen, and oxygen were determined on elemental analyzer (Elementar, vario EL cube). Thermogravimetric-mass spectrometry (TG-MS) measurements were conducted to further determine the surface functional groups using thermogravimetric analyzer (Setaram Setsys Evolution 16/18) and mass spectrometer (Pfeiffer, OMNI star). The samples were heated from ambient temperature to $1000{ }^{\circ} \mathrm{C}$ at a heating rate of $10{ }^{\circ} \mathrm{C}$ $\min ^{-1}$ under Ar atmosphere.

\subsection{Electrochemical Measurements}

A LIR2025 coin-type cell is assembled with metallic $\mathrm{Na}$ as counter electrode in an argon-filled glove box to measure the electrochemical performance. For the working 
electrode preparation, a mixture of the active materials, Super P and polyvinylidene difluoride (PVDF) (7:2:1, in wt \%) in N-methyl-2-pyrrolidone (NMP) solvent was coated on the $\mathrm{Cu}$ foil collector and then dried at $100{ }^{\circ} \mathrm{C}$ under vacuum for $12 \mathrm{~h}$. The mass loading of the active material in the working electrode was about $1.0 \mathrm{mg} \mathrm{cm}^{-2}$. The electrolyte was $1 \mathrm{M} \mathrm{NaClO}_{4}$ mixed with ethylene carbonate (EC) and propylene carbonate (PC) (1:1 by volume) with 5 wt \% fluoroethylene carbonate (FEC) as additive. Cyclic voltammetry $\left(\mathrm{CV}, 0.01-3 \quad \mathrm{~V}, \quad \mathrm{vs} \quad \mathrm{Na} / \mathrm{Na}^{+}\right)$curves and the electrochemical impedance spectra (EIS, $0.01 \mathrm{~Hz}$ to $100 \mathrm{kHz}$ ) were recorded on the CHI1000C and CHI660E electrochemical workstation, respectively.

\section{TG-MS SPECTRAL ANALYSIS}

Thermogravimetric-Mass spectrometry (TG-MS) tests were conducted to further investigate the various proportions of active $\mathrm{O} / \mathrm{N}$ species produced from the mechanochemical modification. The O-containing groups can be decomposed into $\mathrm{CO}$ and $\mathrm{CO}_{2}$ at different temperatures under inert atmospheres. For instance, $\mathrm{CO}$ is released from ketones or aldehydes at a low-temperature range of $200-400{ }^{\circ} \mathrm{C}$, from phenols or ethers at around $600-800{ }^{\circ} \mathrm{C}$ and from quinones at a high-temperature range of $750-1000{ }^{\circ} \mathrm{C}$. The $\mathrm{CO}_{2}$ gas can be generated from carboxylic acid groups at a low-temperature range of $150-450{ }^{\circ} \mathrm{C}$ and from lactones at $600-800{ }^{\circ} \mathrm{C}$. In addition, carboxylic anhydrides release $\mathrm{CO}$ and $\mathrm{CO}_{2}$ simultaneously at $400-650{ }^{\circ} \mathrm{C}$. 

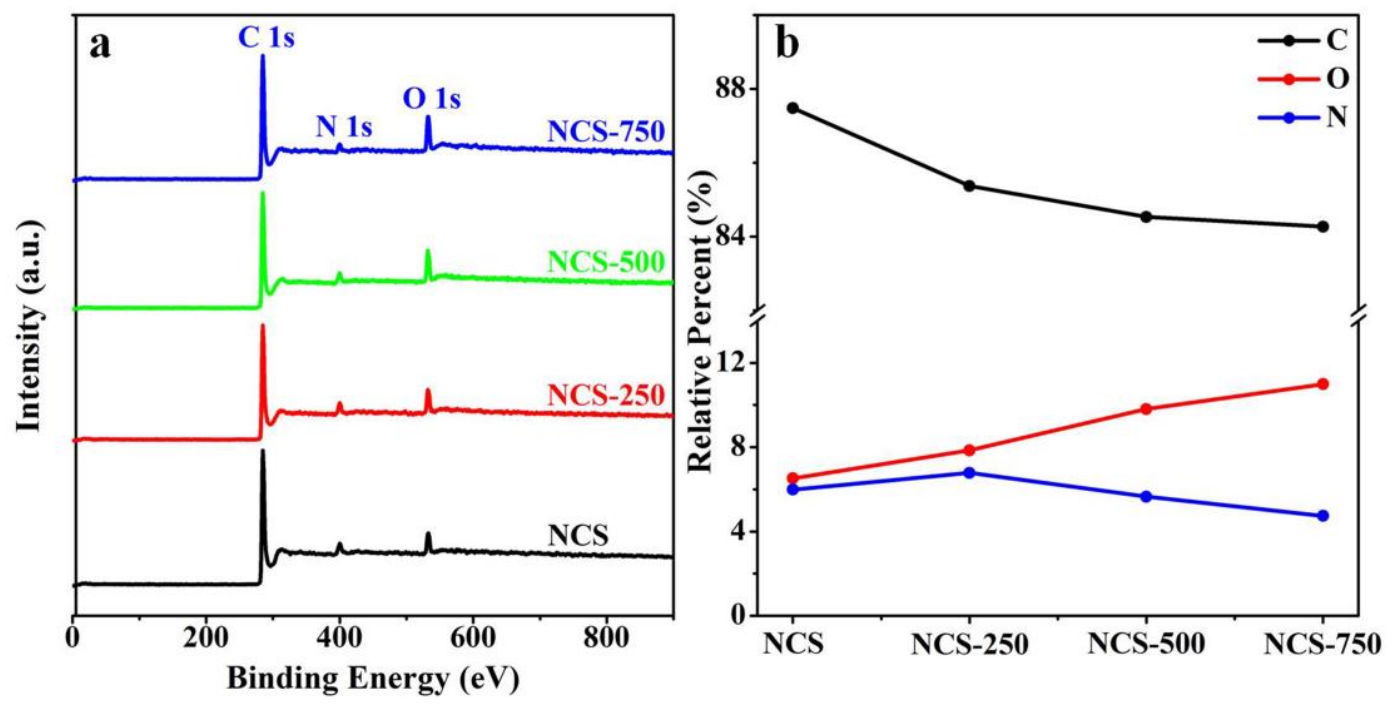

Figure S1. (a) XPS survey spectra and (b) the C, O, N contents of all samples. 

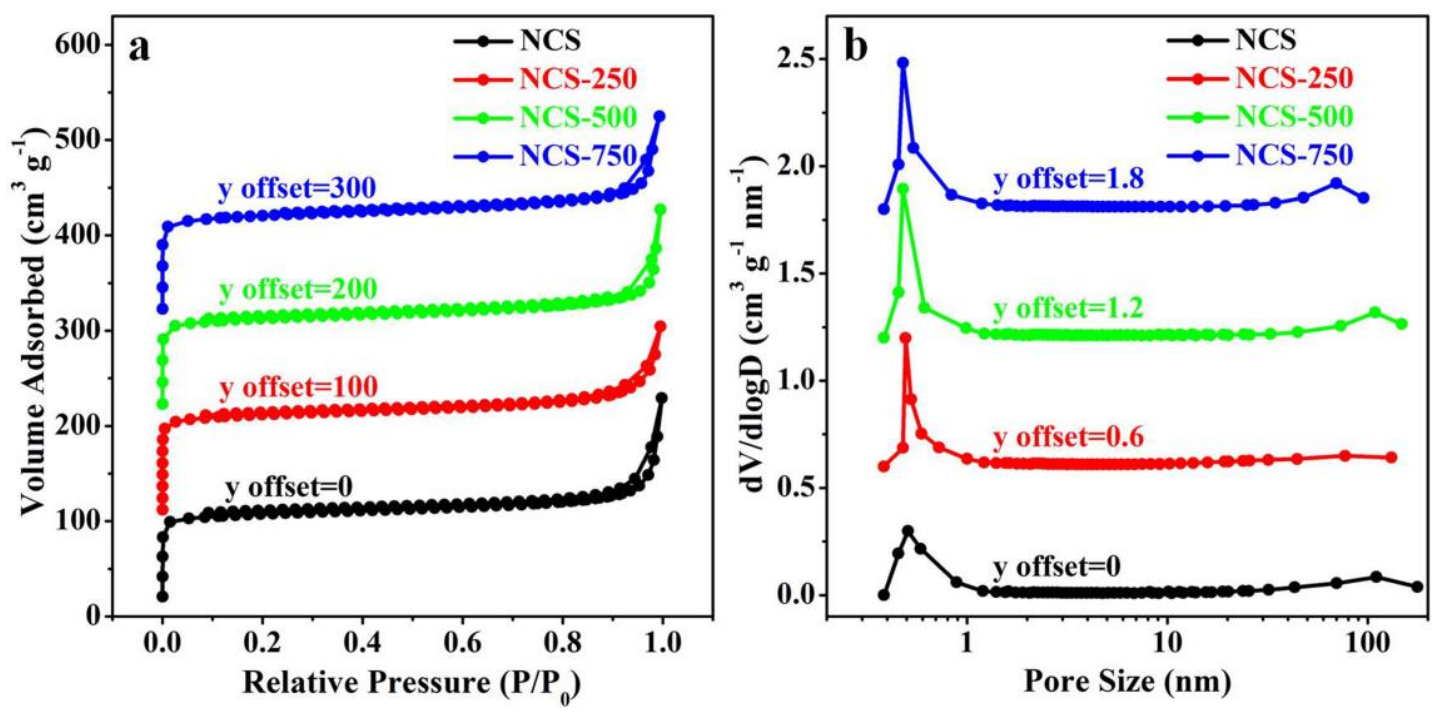

Figure S2. (a) Nitrogen adsorption-desorption isotherms and (b) pore size distribution curves of all samples applying the non-local-density functional theory (NLDFT) method. 

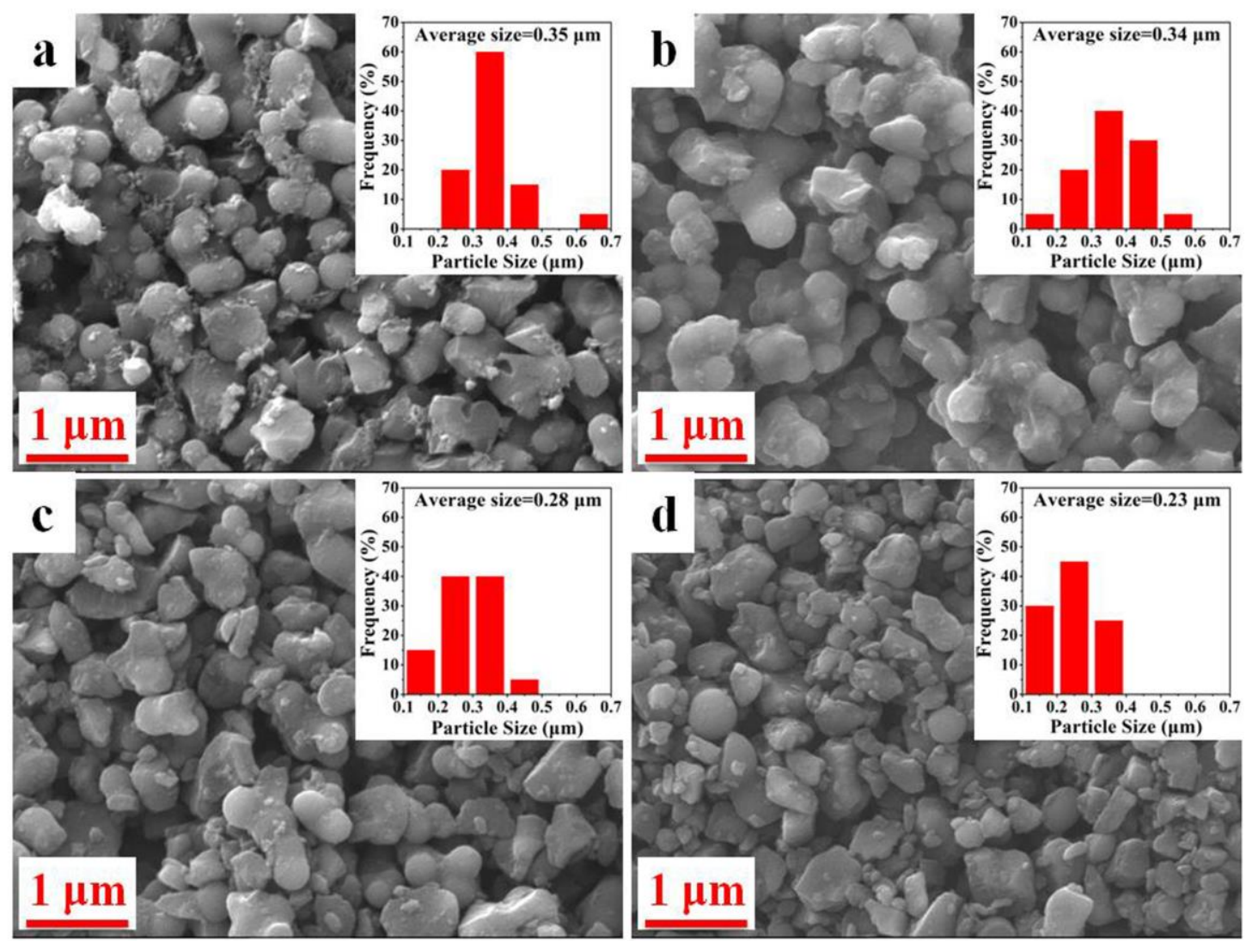

Figure S3. SEM images of (a) NCS, (b) NCS-250, (c) NCS-500, and (d) NCS-750. 


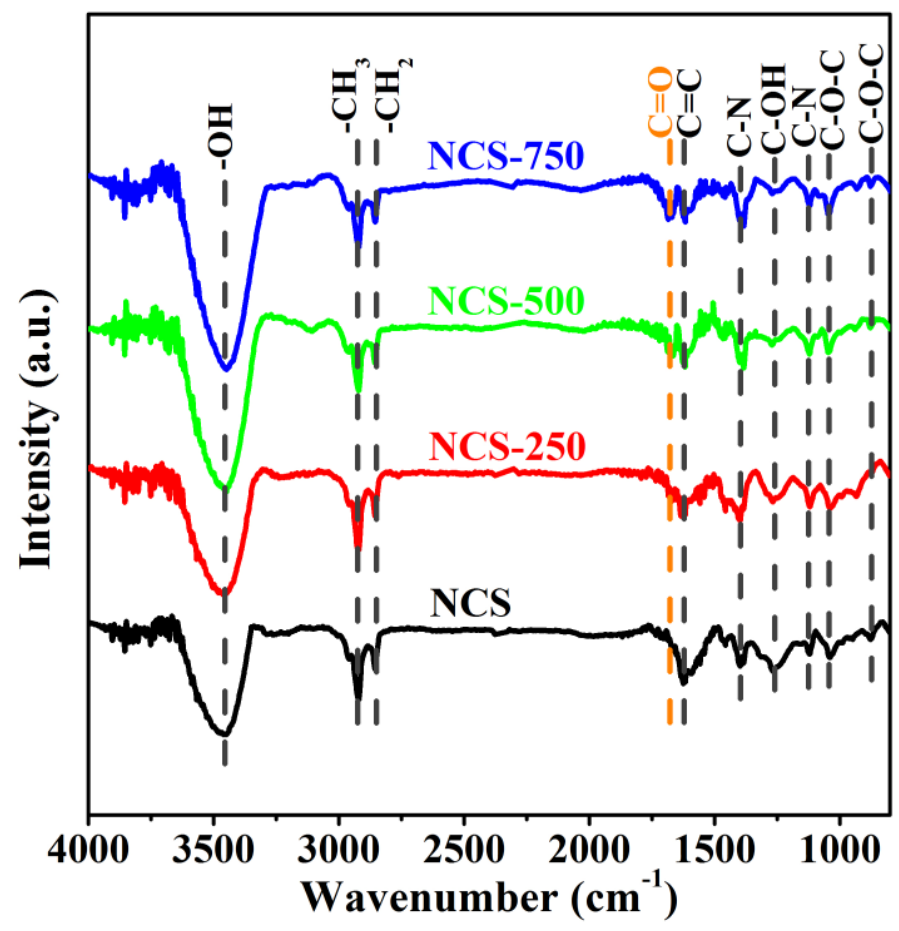

Figure S4. DRIFTS spectra of all samples. 

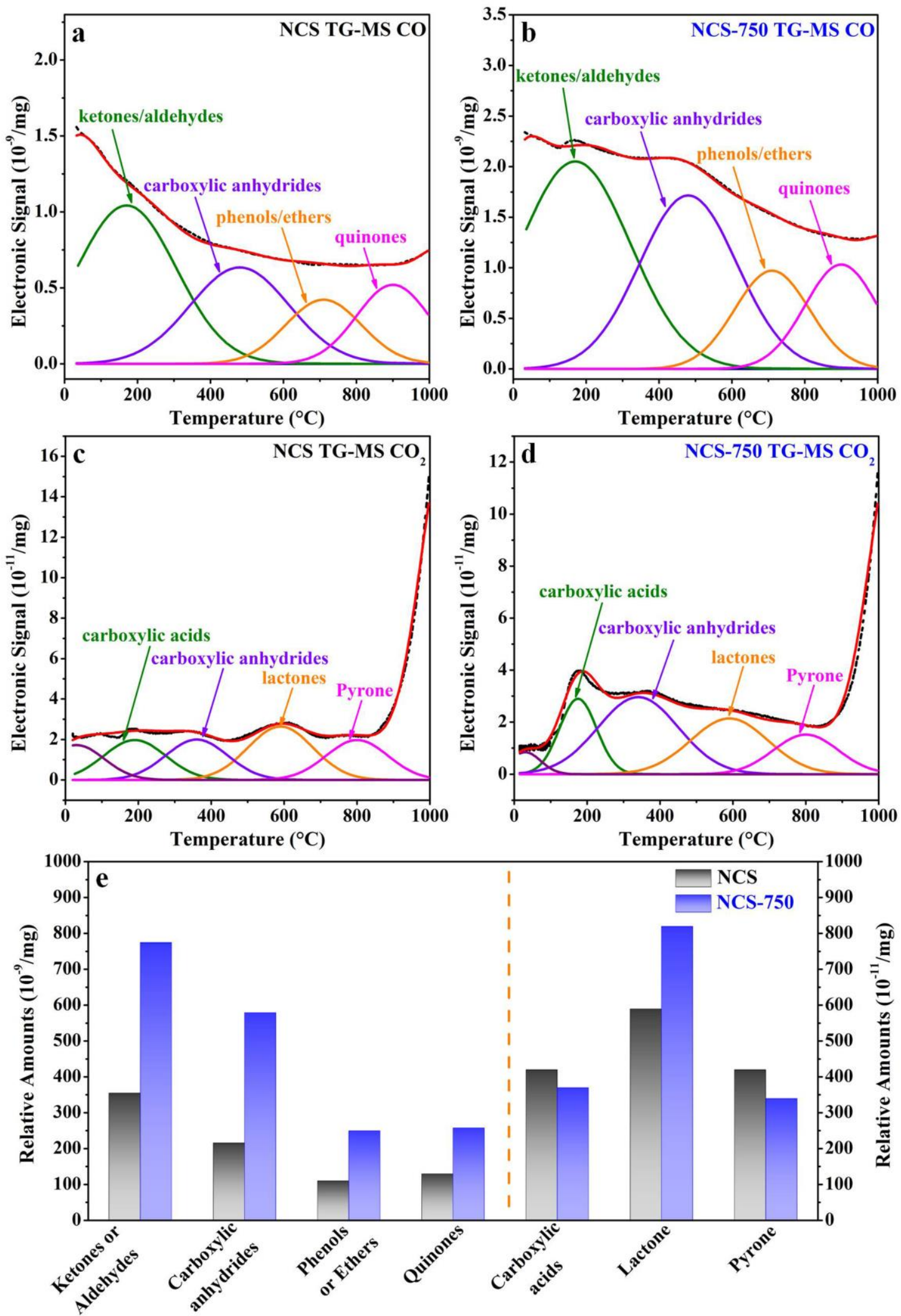

Figure S5. TG-MS $(\mathrm{a}, \mathrm{b}) \mathrm{CO}$ and $(\mathrm{c}, \mathrm{d}) \mathrm{CO}_{2}$ evolution profiles of NCS and NCS-750 samples and (e) the relative amounts of different OFGs. 

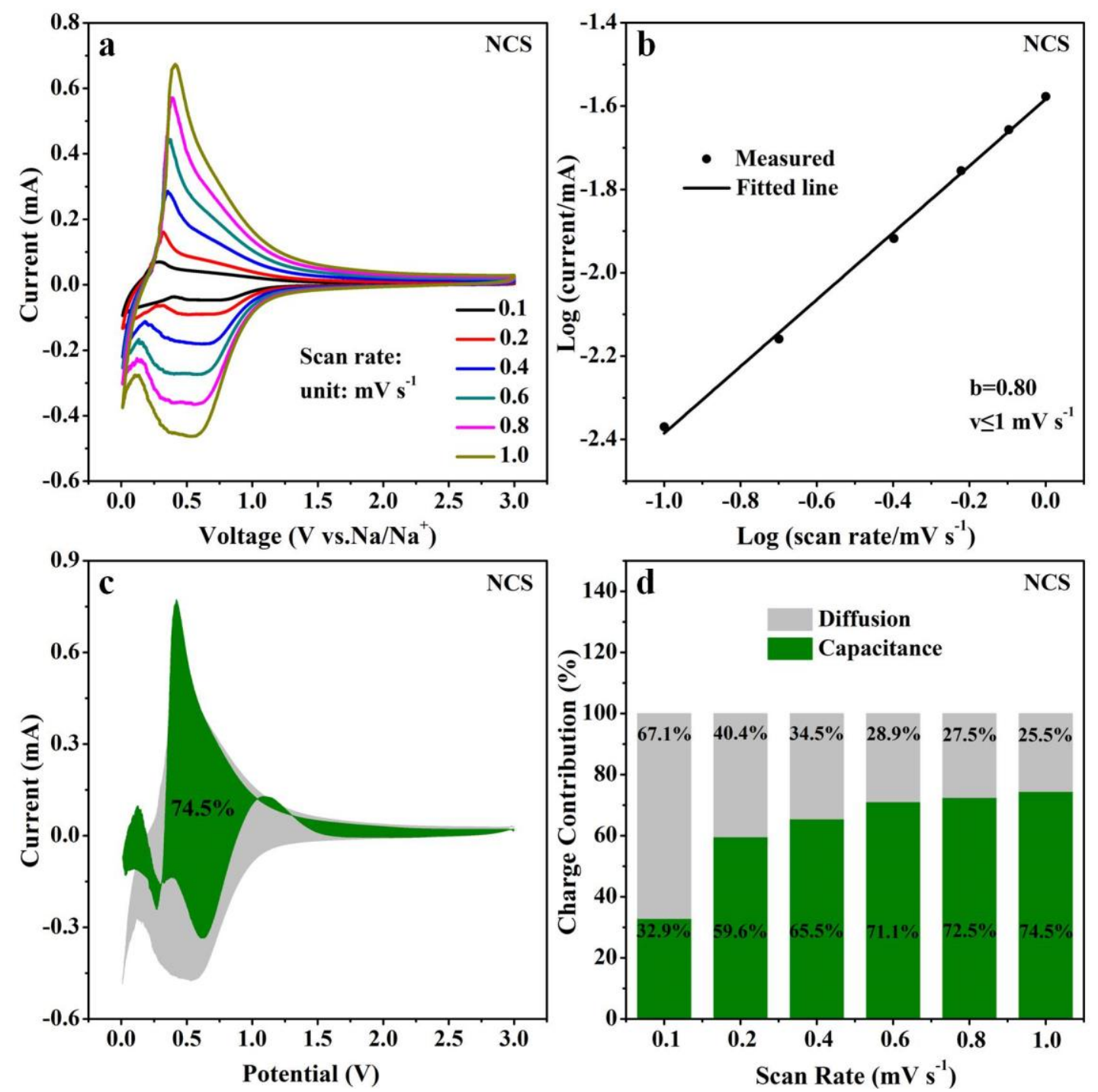

Figure S6. (a) $\mathrm{CV}$ curves at various scan rates from 0.1 to $1.0 \mathrm{mV} \mathrm{s}^{-1}$. (b) Linear relationship between $\log i$ and $\log v$. (c) Capacitance contribution (green region) at $1.0 \mathrm{mV} \mathrm{s}^{-1}$. (d) Percentage of surface capacitance contribution (green region) at different sweep rates for the NCS anode. 
Table S1. Elemental compositions of all samples from elemental analysis.

\begin{tabular}{|ccccc|} 
Samples & N $(w t \%)$ & O $(w t \%)$ & C $(w t \%)$ & H $(w t \%)$ \\
\hline NCS & 7.03 & 10.73 & 80.52 & 1.72 \\
\hline NCS-250 & 7.08 & 9 & 82.13 & 1.79 \\
\hline NCS-500 & 6.98 & 9.66 & 81.58 & 1.78 \\
\hline NCS-750 & 6.20 & 10.91 & 81.04 & 1.92 \\
\hline
\end{tabular}


Table S2. Textural properties of NCS, NCS-250, NCS-500, and NCS-750.

\begin{tabular}{|c|c|c|c|c|}
\hline Sample & $\operatorname{SBET}\left(m^{2} g^{-1}\right)^{a}$ & $V_{t}\left(\mathrm{~cm}^{3} \mathrm{~g}^{-1}\right)^{b}$ & $V_{\text {micro }}\left(\mathrm{cm}^{3} \mathrm{~g}^{-1}\right)^{\mathrm{c}}$ & $V_{\text {meso }}\left(\mathrm{cm}^{3} \mathrm{~g}^{-1}\right)^{d}$ \\
\hline NCS & 365.43 & 0.30 & 0.17 & 0.13 \\
\hline NCS-250 & 377.32 & 0.29 & 0.17 & 0.12 \\
\hline NCS-500 & 379.93 & 0.31 & 0.17 & 0.14 \\
\hline NCS-750 & 417.19 & 0.34 & 0.19 & 0.15 \\
\hline
\end{tabular}

${ }^{a}$ Surface area was calculated with Brunauer-Emmett-Teller (BET) method. ${ }^{\mathrm{b}}$ The total pore volume was determined at a relative pressure of $0.99 .{ }^{\mathrm{c}}$ Micropore volume was determined by applying the non-local-density functional theory (NLDFT) method. ${ }^{d}$ Mesopore volume was obtained by the difference between pore volume $\left(\mathrm{V}_{\mathrm{t}}\right)$ and micropore volume $\left(\mathrm{V}_{\text {micro }}\right)$. 